\title{
Diagnóstico da Presença Feminina nos Cursos Superiores e no Mercado de Trabalho em Tecnologia da Informação no Estado do Pará
}

\author{
Yomara Pinheiro Pires \\ Faculdade de Computação - FACOMP \\ Castanhal, Brasil \\ yomara@ufpa.br \\ Liviane Rego \\ Instituto de Ciências Sociais Aplicadas - ICSA \\ Belém, Brasil \\ liviane@ufpa.br
}

\begin{abstract}
Although women's participation in the Information Technology (IT) market has increased in recent decades, it remains a predominantly male area. One of the factors in this difference is in socio-cultural issues where the social construction of gender roles is limiting women's insertion and permanence in this sector. This work aims to make a diagnosis about the presence of women in higher education courses and in the IT labor market in the state of Pará. The main sources of data used were the governmental public databases of the General Register of Employees and Unemployed (CAGED), the Census of Higher Education, made available (INEP) and the National Household Survey (PNAD). The analyzed data indicated that in the state of Pará, we have the male predominance on the sector either on the superior courses as on the work market and wage inequalities. Despite the increase in the entry of women in academic-scientific careers, in the IT labor market.
\end{abstract}

\section{KEYWORDS}

Relações de Gênero, Computação, Ensino Superior, Mercado de TI e Gênero

\section{INTRODUÇÃO}

Nas últimas décadas, o número de mulheres que ingressam em alguma carreira na área de TI aumentou consideravelmente, mas mesmo assim elas ainda são minoria em relação ao quantitativo masculino, conforme mostra pesquisas do Instituto Nacional de Estudos e Pesquisas Educacionais Anísio Teixeira (INEP) [1]. Através desta pesquisa, foi possível observar que de 2008 a 2018 o número de mulheres, em média, representa apenas $15 \%$ do número de ingressantes na área, o que demonstra que em nossa sociedade a área ainda é predominantemente dominada por homens.

Apesar de atualmente a área de TI ter maior participação masculina, o início de sua história foi marcado por uma importante inserção feminina, como Ada Lovelace (responsavel por criar o primeiro algoritmo da história)[2], Grace Hopper (que ajudou no desenvolvimento de um dos primeiros computadores)[2], entre outras. Mesmo tendo mulheres importantes que revolucionaram a área, cada uma em suas respectivas épocas, seus nomes nem sempre são lembrados, ou mesmo mencionados, e isto deve-se principalmente

\author{
Maria Roselene Alves Lima \\ Faculdade de Computação - FACOMP \\ Castanhal, Brasil \\ maria.alves.lima@castanhal.ufpa.br
}

\author{
Francisco Aguinaldo de Albuquerque Júnior \\ Instituto de Tecnologia - ITEC \\ Belém, Brasil \\ jralbbuquerque@gmail.com
}

pelo contexto social, em que se estabeleceu a relação entre tecnologia e masculinidade[3], onde o acesso a uma formação acadêmica e o preconceito de mulheres na área de exatas ainda é uma barreira.

$\mathrm{O}$ reduzido número de mulheres que ingressam em carreiras na área da (TI) também repercutem no mercado de trabalho, onde segundo pesquisa realizada pela SOFTEX [4], a partir de dados da RAIS, em um recorte de gênero entre o período de 2007 a 2017, houve uma queda no número de participação da mulher no mercado de trabalho, que diminuiu de $24 \%$ para cerca de $20 \%$. Fora do país também encontra-se realidade semelhante: nos EUA, por exemplo, o último censo estima que elas ocupam apenas $25 \%$ dos empregos em TI [5] e em 2019, o Google revelou que apenas 30\% de todos os seus colaboradores são do sexo feminino [6].

As dificuldades da inserção e manutenção das mulheres nessa área estão relacionadas a questões sócio-culturais, em especial questões de gênero [7-10], [4, 11], sendo a falta de estímulos durante a infância e/ou juventude, passados pela família e/ou escola, os principais influenciadores para a escolha da profissão. Este problema se estende durante o ensino superior. O preconceito continua sendo um dos principais fatores para que as mulheres abandonem os cursos de TI. De acordo com a Pesquisa Nacional por Amostras de Domicílios (PNAD) realizada em 2020, cerca de 79\% das mulheres que ingressam nos cursos relacionados à área de TI acabam por abandonar nos anos iniciais. Soma-se a este, fatores relacionados à falta de referências femininas na área, obrigações familiares e questões financeiras.

Outro fator importante a ser observado é que o número de mulheres vem aumentando em carreiras acadêmico-científica nas últimas décadas. No entanto, observa-se que ainda são minoria nas áreas de exatas e engenharias. Isto pode ser observado com os dados do relatório da UNESCO [7]. Neste mesmo relatório, nota-se também que dentro da população estudantil mundial de mulheres apenas 3\% das matrículas são na área de TI.

O objetivo deste trabalho foi fazer um diagnóstico acerca da presença feminina nos cursos superiores e no mercado de trabalho de TI no estado do Pará. Neste sentido, busca-se investigar, por meio de analises bibliograficas e quantitativas nas principais fontes de dados públicas governamentais do Cadastro Geral de Empregados e Desempregados (CAGED), do Censo da Educação Superior, 
disponibilizado pelo INEP e do Censo e PNAD contínua do Instituto Brasileiro de Geografia e Estatística (IBGE).

Este trabalho integra as ações do projeto Meninas Pai D'éguas pertencente ao Programa Meninas Digitais da Sociedade Brasileira de Computação (SBC). Espera-se com este uma melhor compreensão da atuação feminina em TI no estado do Pará e, consequentemente, auxiliar em ações que visam mitigar este problema de gênero.

\section{FUNDAMENTAÇÃO TEORICA}

Nesta seção serão apresentados alguns estudos relacionados a participação da mulher na STEM, sigla em inglês para Science, Technology, Engineering and Mathematics (Ciência, Tecnologia, Engenharia e Matemática, em português) e no mercado de TI. Estes estudos são oriundos de entidades reconhecidas mundialmente, como a Organização das Nações Unidas (ONU), UNESCO e pesquisas academicas sobre o assunto. Os mesmos possibilitam uma maior compreensão da atuação feminina em TI no estado do Pará.

\subsection{Mulheres e STEM}

A significativa desigualdade entre homens e mulheres na área de TI, seja nos cursos superiores ou no mercado de trabalho, tem como premissa o contexto histórico social, onde, desde muito cedo, ideias estereotipadas sobre os papéis sociais dos gêneros são desenvolvidas.

De acordo com o relatório da UNESCO de 2018, que discute educacao de meninas e mulheres em ciencias, tecnologia, engenharia e matematica (STEM):

Os estereótipos de gênero que transmitem a idéia de que os estudos e as carreiras em STEM são domínios dos homens podem afetar negativamente o interesse, o envolvimento e os resultados em STEM das meninas, e podem desencorajá-las a seguir carreiras em STEM. As meninas que assimilam esses estereótipos têm níveis de autoeficácia e de confiança em suas habilidades mais baixos do que os dos meninos. A autoeficácia afeta em medida considerável tanto os resultados da educação em STEM quanto as aspirações por carreiras em STEM. (Decifrar o código: educação de meninas e mulheres em ciências, tecnologia, engenharia e matemática (STEM). - Brasília: UNESCO, 2018.)

Ainda neste relatório, é mencionado que a participação feminina na educação em STEM deve ser considerada no contexto de seu acesso em todos os seus níveis. Visto que tem um papel essencial na transformação social de homens e mulheres. Além disso, a educação em STEM é fundamental para a Agenda 2030, em seus Objetivos de Desenvolvimento Sustentavel (ODS) 4 e 5, onde discute a educação e a igualdade de gênero e empoderamento das mulheres.

Apesar do aumento no número de mulheres no ensino superior, este aumento concentra-se nas áreas de educação, saúde, humanidades e ciências sociais [7]. Enquanto que os alunos do sexo masculino são prevalencia nos cursos das áreas de exatas e tecnologias $[1,7]$. De acordo com pesquisa INEP [12] 71,3\% das matrículas em cursos de licenciatura são do sexo feminino, enquanto $28,7 \%$ são do sexo masculino. De acordo com [13], ao considerar-se publicações de artigos científicos relacionados à área de Matemática e Computação, $75 \%$ destes são publicados por homens.

Segundo [11], no Brasil a participação feminina em áreas relacionadas a exatas e TI representam apenas $14 \%$ do total de alunos matriculados. O estudo apresentado em [14] realiza uma importante projeção, visto que a participação feminina em cursos de Ciência da Computação reduz-se a uma taxa de $0,4 \%$ a cada ano, caso não haja adoção de medidas preventivas para reverter este quadro, a presença de mulheres em cursos da área se extinguirá em, aproximadamente, 2050.

Neste sentido, a disparidade de gênero no ensino superior e no mercado de TI vem sendo amplamente discutida e estudada [7-10], [3], [15-17].

\subsection{A mulher e o mercado de trabalho em TI}

Dados do IBGE de 2015, apontam uma predominância feminina na população $(51,6 \%)$. No entanto, apesar de serem mais qualificadas recebem apenas cerca de 72,7\% do salário pago aos homens, mesmo exercendo as mesmas funções [18]. No mercado de TI esta realidade não é diferente, dados do Brasscom [19] apontam que os homens predominam nas funções técnicas $(76,1 \%)$ enquanto que as mulheres têm maior representatividade nas funções administrativas, teleatendimento e recursos humanos $(64,9 \%)$, ainda neste mesmo relatório é mostrado que existe a disparidade de gênero e raça no setor de TI.

Dados de 2018 demonstram que trabalhadores brancos e asiáticos somavam $59 \%$ no setor, sendo $37 \%$ homens e $22 \%$ mulheres, entre os trabalhadores negros, pardos ou indigenas, $11 \%$ são mulheres e $19 \%$ homens. Estes números demonstram a desproporção de acesso ao mercado de trabalho por esse grupo, mesmo considerando que a população nacional feminina e negra ainda é majoritária.

Já o relatório Cepal [20] na edição de 2018 traz no seu capítulo $\mathrm{V}$, informações estatísticas referentes a atuação das mulheres no mercado de trabalho, mostra ainda que apesar de alguns problemas relacionados às questões culturais e educacionais as mulheres estão ganhando espaço nos setores de serviços e de tecnologia.

As estatísticas mostram que a desigualdade de gênero tem diminuído na última década, mas segundo o relatório do Fórum Econômico Mundial - (WEF), publicado em 2019, se a evolução dos direitos das mulheres continuar nesse ritmo essa igualdade se dará somente em 2095. Levando em conta vários fatores, o relatório mostra que será necessário pelo menos 257 anos para que se atinja a paridade entre os gêneros.

O mesmo relatório mostra que apenas $55 \%$ das mulheres adultas estão no mercado de trabalho, enquanto que os homens ocupam $78 \%$ desse mercado. Elas ocupam posições semelhantes a eles e ganham em média $40 \%$ menos. Essa disparidade diminui consistentemente nos países que ocupam a Organização para Cooperação e Desenvolvimento Econômico (OCDE) e aumentam nas economias emergentes e em desenvolvimento.

Mostra-se ainda mais um dado que é preocupante, no ranking de igualdade de salários, dos 142 países avaliados, o Brasil é o penúltimo entre os países das Américas, ficando em $124^{\circ}$ posição e perdendo apenas para o Chile. 
Neste sentido, para que uma real equidade seja alcançada se faz necessário ações e mudanças para mitigar este problema em diversos níveis, tanto na estrutura das sociedades, quanto nas organizações e nas famílias. Por não ser somente brasileira e sim mundial a responsabilidade por esse processo deve ser partilhada por todas essas esferas pois nenhuma delas conseguirá sozinha uma transformação sustentável.

Portanto é importante a criação de políticas públicas que preencham a demanda na área que por sua vez encontra-se em alta crescente e sem mão de obra suficiente, podendo assim gerar danos tanto de ordem econômica como também social.

\section{MATERIAIS E MÉTODOS}

A metodologia utilizada na condução deste trabalho, alinhado ao objetivo de caracterizar o mercado profissional de TI de uma forma contextualizada e regionalizada levando em consideração aspectos relacionados ao gênero, possui caráter exploratório e quantitativo. Buscou-se fazer um levantamento sobre particularidades regionais sobre a área educacional na área, bem como sobre as diferenças de gênero no mercado profissional.

Visando fazer o levantamento dos diversos cenários existentes que norteiam a área de TI e embasar as análises geradas neste trabalho, foram utilizadas diversas fontes de dados relacionados com o mercado de trabalho, a área educacional e características populacionais do país.

Sobre o mercado de trabalho paraense, foram utilizados os dados CAGED, pertencente ao Ministério da Economia que possui informações mensais sobre o número de admissões e desligamentos de empregados sob regime da Consolidação das Leis do Trabalho (CLT). Para esta pesquisa, foram levantadas apenas ocupações na área de TI do ano de 2010 a 2019.

Os dados educacionais foram coletados a partir do Censo da Educação Superior, disponibilizado pelo INEP, que possui informações sobre a infraestrutura das instituições de ensino superior, vagas oferecidas, candidatos, matrículas, ingressantes, concluintes e docentes. Este trabalho levantou dados sobre ingressantes e concluintes nos cursos superiores no Brasil dos anos de 2003 à 2018. Destaca-se que os dados do INEP até o momento desta pesquisa, ainda não haviam sido atualizados com os anos de 2019 e 2020.

Por fim, utilizou-se também bases de dados do IBGE (Censo e PNAD contínua), que possuem características acerca das condições gerais da população, educação, trabalho, rendimento e habitação. Neste trabalho foram utilizadas informações dos censos de 2000 e 2010 e da PNAD até 2019.

É importante destacar que a etapa de coleta de dados foi uma das etapas que mais demandou tempo do trabalho devido a escassez e dificuldade de conseguir dados oficiais acerca do assunto. Após a etapa de coleta dos dados, seguiu-se a etapa de tabulação dos mesmos, onde dados foram selecionados e organizados em planilhas e gráficos para que pudessem ser analisados.

Com a base do INEP, foi possível gerar relacionamentos interessantes acerca do números de ingressantes e concluintes nas universidades em cursos de Tecnologia de Infomação e Comunicação (TIC) por sexo, por região, por estado e por raça. Tal análise apresenta um diagnóstico sobre como está o acesso ao ensino superior permitindo assim sejam levantadas possíveis dificuldades enfrentadas para a sua conclusão de forma bem ampla e regionalizada.

Através da análise de dados provenientes do CAGED foi possível traçar a diferença do acesso ao mercado de trabalho de TI por homens e mulheres, bem como fazer um diagnóstico da evolução da oferta de empregos tanto para homens quanto para mulheres.

Já a base de dados provenientes do IBGE foram importantes para que além das informações acerca da formação profissional e do mercado de trabalho, fosse também avaliada questões sobre rendimento e informações gerais de educação.

Os resultados obtidos foram analisados do ponto de vista quantitativo. Primeiramente, foram selecionadas as variáveis da pesquisa: cor, gênero, dados de ingressantes e concluintes em IES, admissões e demissões segundo a Classificação Brasileira de Ocupações (CBO) dispostas no CAGED. Em seguida, foram realizadas as análises descritivas como distribuições das frequências e médias.

Cabe aqui destacar que o CAGED considera apenas os funcionários contratados pelas empresas em regime de Consolidação das Leis do Trabalho (CLT), ou seja, somente empregos formais, não levando em consideração profissionais prestadores de serviços (PJs), autônomos e empreendedores, como exemplo Startups.

\section{AVALIAÇÃO E RESULTADOS}

Os resultados apresentados são oriundos de análises nas bases de dados já descritas na seção 3, que estão divididas em analisar a participação feminina no estado do Pará em relação aos cursos superiores e também analisar a sua participação no mercado de trabalho de TI também no referido estado.

\subsection{Participação feminina em cursos superiores no estado do Pará}

Nesta análise buscou-se prioritariamente estabelecer a relação de ingressantes e concluintes do estado do Pará com o quantitativo brasileiro e demais estados da região norte. Também buscou-se o entendimento de como está o quantitativo de ingressantes e concluintes nas Instituições de Ensino Público (IES) por gênero e cor. Os resultados são descritos a seguir.

A figura 1 exibe, em valores absolutos, o número de ingressantes e concluintes nos cursos superiores no Brasil entre o período de 2003 à 2018. Percebeu-se que o recrutamento masculino é eficiente, mas a persistência da mulher no ensino superior é maior, estando equiparado ao número de concluintes do sexo masculino.

Em percentuais, percebe-se que do total de ingressantes masculinos apenas $17 \%$ concluem enquanto $27 \%$ das mulheres chegam ao fim do curso. Isto mostra que a evasão masculina é maior. Estes dados apontam para a realização de uma pesquisa mais aprofundada e adoção de políticas públicas.

$\mathrm{Na}$ figura 2, em uma análise do quantitativo de ingressantes e concluintes entre os estados que compõem a região norte do país percebe-se que o estado do Pará contribui com $0,48 \%$ do total. Segundo dados do IBGE 2020, o Pará é o estado mais populoso da região norte com 8.690.745 habitantes, seguido do Amazonas com 4.207.714 habitantes. Ainda assim, perde em número de ingresso em IES. Ou seja, apesar de ser o estado mais populoso da região norte, o número de ingressantes e concluintes não acompanha este percentual. 


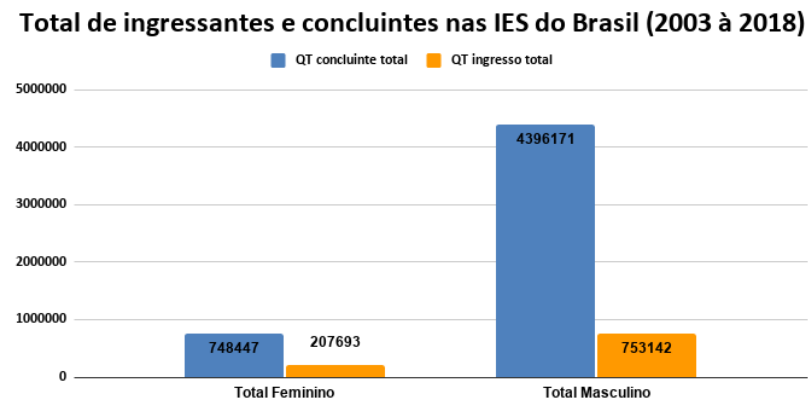

Figure 1: Total por gênero de alunos ingressantes e concluintes em IES públicas brasileiras de 2003 a 2018. Fonte: Autores

Segundo pesquisa da Abres [21] realizada em 2018, apenas 36,68\% dos ingressantes chegam a concluir o curso, sendo 259.302 no setor público e 1.004 .986 no privado. A falta de condições financeiras é uma das principais razões pela não conclusão ou abandono do curso.

Vale destacar que na base de dados consultada, não foram observados registros sobre ingressantes do sexo feminino e concluintes para ambos os sexos no estado de Rondônia. No estado do Tocantins também não foram observados registros de concluintes do sexo feminino.

Observa-se também na figura 2 que o estado do Pará é o segundo estado em total de ingressantes e concluintes. De acordo com dados da Semesp [22], a Região Norte possui a menor quantidade de matrículas do país, registrando 692 mil matrículas no total em 2018 , representando apenas $8,2 \%$ do total dos estudantes do ensino superior brasileiro.

\section{Ingressantes e concluintes em IES por estados}

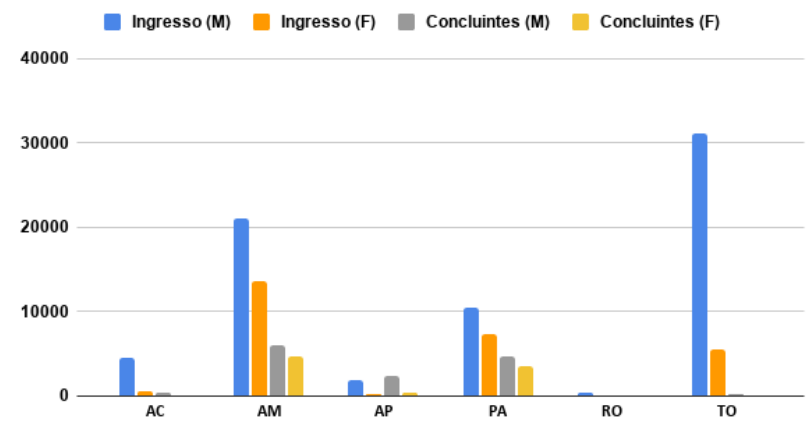

Figure 2: Distribuição de ingressantes e concluintes por estados da região norte de 2003 à 2018. Fonte: Autores

A figura 3 exibe a distribuição por cor e gênero de alunos concluintes e ingressantes em IES públicas no período de 2003 a 2018.

No que se refere a ingressantes, percebe-se que $64 \%$ das pessoas brancas, são homens. Quanto aos indigenas, 60\% dos ingressantes são do sexo feminino e, $51 \%$ dos pardos são homens. Chama atenção
Ingressantes e concluintes em IES públicas

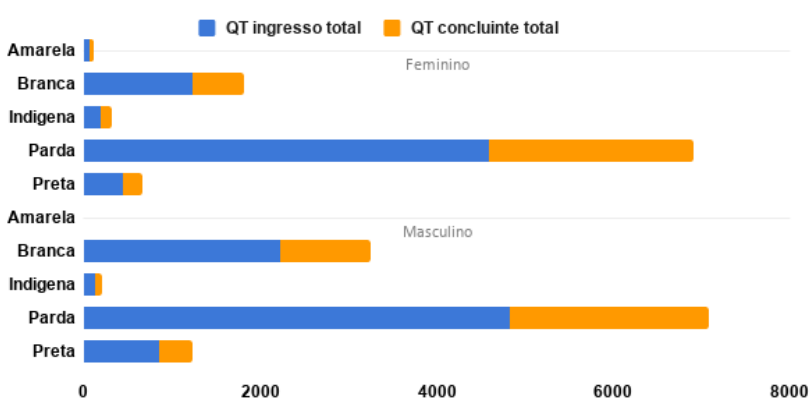

Figure 3: Distribuição por cor e gênero de alunos ingressantes e concluintes em IES públicas de 2003 a 2018. Fonte: Autores

Table 1: Percentuais de ingressantes e concluintes distribuidos por raça e sexo. Fonte: Autores.

\begin{tabular}{cccl}
\hline Raça & Sexo & \%Ingressantes & \%Concluintes \\
\hline amarelo & feminino & $0,45 \%$ & $0,80 \%$ \\
& masculino & 0 & 0 \\
branco & feminino & $0,32 \%$ & $0,64 \%$ \\
& masculino & $0,10 \%$ & $0,27 \%$ \\
indigena & feminino & $4,82 \%$ & $13,64 \%$ \\
& masculino & $0,85 \%$ & $2,77 \%$ \\
Pardo & feminino & $2,18 \%$ & $4,76 \%$ \\
& masculino & $0,44 \%$ & $1,37 \%$ \\
Preta & feminino & $0,83 \%$ & $1,71 \%$ \\
& masculino & $0,26 \%$ & $0,78 \%$ \\
\hline
\end{tabular}

que somente $13 \%$ são mulheres ingressantes são pretas. Percentualmente, o número de concluintes brancos, pardos, indígenas e pretos apresenta comportamento parecido ao número de ingressantes.

Em relação aos valores acima descritos na figura 3, o estado do Pará contribui com os seguintes percentuais, tabela 1 .

Observando-se a questão de gênero, figura 4, percebe-se a relevância masculina. Considerando a totalidade de IES públicas e privadas, cerca de $85,5 \%$ são ingressantes do sexo masculino. Destes, $78,4 \%$ são concluintes. Já para o sexo feminino temos $14,5 \%$ ingressantes e $21,6 \%$ concluintes. Estes dados corroboram com a ideia estereotipada da mulher no mercado de TI, onde prevalecem questões socioculturais que diferenciam a qualificação profissional e dificultam o ingresso ou permanência da mulher na área.

A pesquisa realizada em [8] também retrata este aspecto, onde segundo os autores, entre os anos de 2000 a 2013 a presença feminina entre os concluintes de cursos do campo da computação é minoritária. Ainda segundo a referida pesquisa, o ingresso de mulheres na computação ainda sofre com os estereótipos.

Especificamente no estado do Pará, esse padrão de ingressantes e concluintes também pode ser encontrado, conforme descrito em [23], a pesquisa mostra o menor ingresso de mulheres comparados 


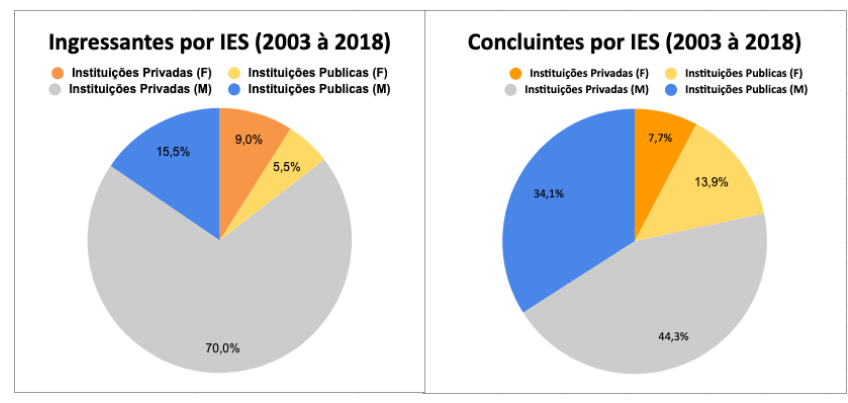

Figure 4: Número de ingressantes e concluintes por IES. Fonte: Autores

com os homens nos cursos de TI de uma Universidade Federal do município de Capitão Poço (PA). Essas diferenças nas universidades também corroboram com as diferenças de admissões no mercado de trabalho na área de TI por sexo, onde a contratação de homens também é maior que mulheres, conforme mostra a figura 5. Acreditase que essa diferença entre os gêneros no mercado de trabalho desestimulem mulheres a buscarem seu ingresso nas universidades, principalmente em cursos predominantemente masculinos, como os da área de TI

\subsection{Participação feminina no mercado de trabalho em TI no estado do Pará}

Visando pontuar o cenário atual do mercado de trabalho paraense, os dados do CAGED foram tabulados e algumas análises foram geradas para o período de 2010 a 2018, conforme demonstrado a seguir.

A figura 5 mostra o número de admissões de homens e mulheres no mercado de trabalho em TI no estado do Pará. Através de sua análise, verifica-se que o número de homens admitidos é muito maior do que o número de mulheres (mais que o dobro em todos os anos, exceto em 2010). Outro aspecto importante a ser destacado nessa análise é que o gráfico, de um modo geral, apresenta-se estável ao longo dos anos analisados. Essa mesma estabilidade também pode ser encontrada no cenário nacional, conforme pode ser observado em [24] ao analisar os números de contratações por sexo em uma empresa pública federal de TI nos anos de 2010, 2013, 2014 e 2015.

Um aspecto importante a ser observado é que há uma estabilidade no número de admissões no mercado de TI contrastando com o crescente número de estudantes egressos de cursos de tecnologia, também no período de 2010 a 2018, conclui-se que o mercado formal paraense não está conseguindo mais absorver toda a mão de obra que é formada anualmente. Analisando a tabela 2, percebe-se que a partir nos últimos 3 anos o número de admitidos representa apenas $50 \%$ (aproximadamente) do valor total dos concluintes no mesmo ano.

A tabela 2 , exibe um comparativo entre as admissões constantes no registro CAGED com os quantitativos de concluintes presentes na base de dados do INEP em um recorte histórico de 2010 à 2018.

Uma outra abordagem é proposta na análise da figura 6, que exibe a diferença entre o número de contratações de homens e mulheres no estado do Pará, por cargo, segundo a funções CBO [25], e utilizada na classificação CAGED. Nele, os valores positivos

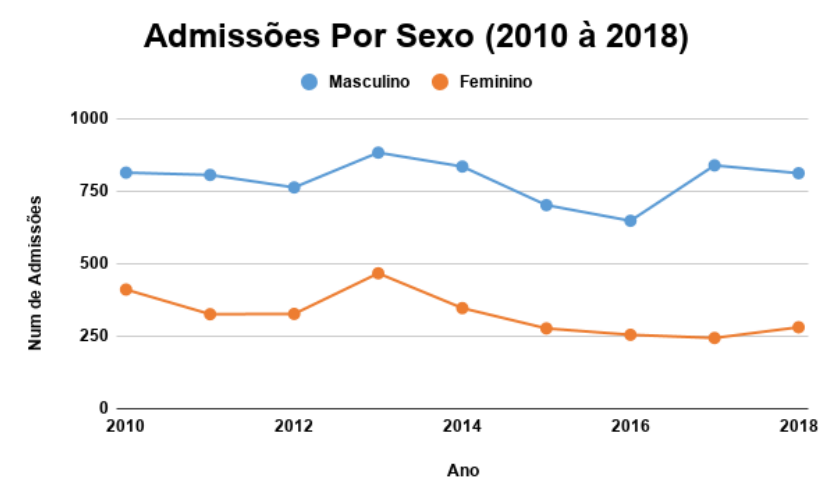

Figure 5: Número de admissões em TI no estado do Pará de 2010 a 2018 por sexo. Fonte: Autores

Table 2: Número de Concluintes e Número de Admissões. Fonte: Autores.

\begin{tabular}{ccc}
\hline Ano & concluinte & admissão \\
\hline 2010 & 32 & 1225 \\
2011 & 191 & 1132 \\
2012 & 432 & 1090 \\
2013 & 463 & 1350 \\
2014 & 442 & 1182 \\
2015 & 689 & 979 \\
2016 & 1951 & 903 \\
2017 & 2275 & 1083 \\
2018 & 1902 & 1093 \\
\hline
\end{tabular}

no eixo $\mathrm{X}$ mostram que houve um aumento em contratações do sexo masculino e, os valores negativos neste mesmo eixo representam um maior número de mulheres contratadas no respectivo período. Através da figura 6, percebe-se que o único cargo em que houve mais contratações de mulheres no período foi o de digitador, cargo esse com menor exigência de qualificação técnica e, consequentemente, menor média salarial.

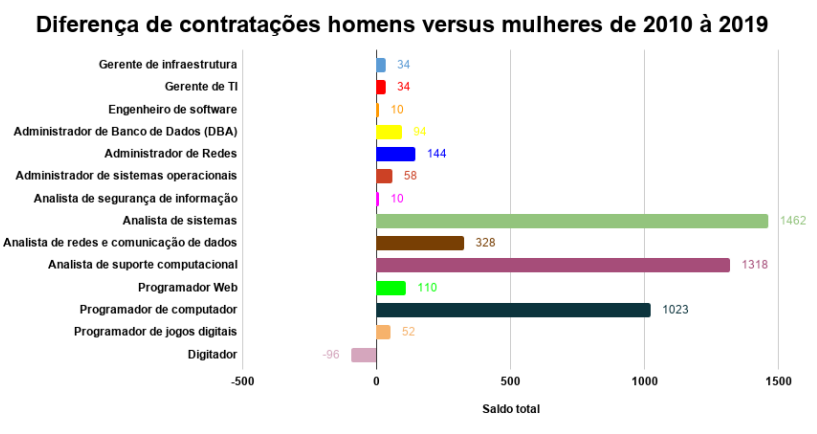

Figure 6: Diferenças de contratações entre homens e mulheres no período de 2010 a 2019 


\subsection{Ações afirmativas}

As ações afirmativas no âmbito do Projeto Meninas Paid'éguas são direcionadas a alunas de ensino médio e dos cursos de Computação da Universidade Federal do Pará dos campi Belém e Castanhal. Tendo como objetivo o incentivo ao ingresso em cursos de ciências exatas, em especial Computação; bem como, a não evasão das alunas já ingressas. Por atuar com alunas de níveis de ensino distintos, foi necessário o desenvolvimento de atividades adequadas as vivências e experiencias escolares de cada. Segundo [26], o principal desafio neste tipo de iniciativa é abordar as atividades de forma adequada aos dois grupos de estudantes: um formado por adolescentes e outro por mulheres no início da fase adulta.

Dentre as ações desenvolvidas até o momento destaca-se: (i)Empoderamento Feminino por meio de cursos como stop motion nas escolas; (ii)- Roda de conversas com relatos de egressas da computação; (iii)- Palestras sobre mulheres na computação e mercado de TI; (iv)- Promoção de atividades nas redes sociais do projeto; (v)Atividades com computação desplugada e robótica a baixo custo alinhado as diretrizes de ensino da computação no ensino básico (SBC) [27] e a Base Nacional Comum Curricular(BNCC) [28]

Diante dos objetivos já mencionados, as ações do Projeto Meninas Paid'éguas visaram contribuir na redução da evasão de seus cursos, uma vez que, ao se envolverem com as atividades do projeto as alunas participantes sentiram-se mais incentivadas e motivadas a concluirem seus cursos.

Quanto as alunas do ensino médio, o projeto contribuiu em desmitificar a cultura de gênero relacionada a computação, incentivando o ingresso destas meninas na área. Além disso, a troca de experiências vivenciadas entre alunas do ensino médio e ensino superior possibilita o aumento de referências femininas na área de computação da região em estudo.

\section{CONSIDERAÇÕES FINAIS}

Segundo dados da PNAD 2019, na população brasileira o número de mulheres no Brasil é superior ao de homens, sendo 51,8\% composta por mulheres e $48,2 \%$ por homens. No entanto, apesar desta prevalência feminina na população, a área de TI tem se caracterizado predominantemente masculina. Tal afirmação apoia-se nos estudos realizados em bases de dados públicas como PNAD, CAGED, IBGE e INEP e, por consultas a relatórios de entidades e organizações como BRASSCOM, ONU, CEPAL e OCDE. Estes resultados também puderam ser observados quando analisados na perspectiva dos cursos superiores e no mercado de TI no estado do Pará entre os anos de 2003 a 2018.

Analisando-se os valores de ingressantes e concluintes nos cursos superiores percebeu-se que, apesar do estado do Pará ser o mais populoso da Região Norte com 8.690.745 habitantes, perde para o estado do Amazonas em número de ingressantes e concluintes.

Cabe destacar que a Região Norte possui a menor quantidade de matrículas do país, onde em 2018 representou apenas $8,2 \%$ do total dos estudantes do ensino superior brasileiro.

Ao verificar a questão de cor em cursos superiores percebeuse que $64 \%$ dos ingressantes são homens brancos. Quanto aos indigenas, tem-se $60 \%$ dos ingressantes do sexo feminino e, $51 \%$ homens pardos. Somente $13 \%$ são mulheres pretas. Percentualmente, o número de concluintes brancos, pardos, indígenas e pretos apresenta comportamento parecido ao número de ingressantes.

Quanto ao sexo, percebeu-se a prevalência masculina. Considerando a totalidade de IES públicas e privadas, cerca de $85,5 \%$ são ingressantes do sexo masculino. Destes, $78,4 \%$ são concluintes. Já para o sexo feminino temos $14,5 \%$ ingressantes e $21,6 \%$ concluintes.

Ao analisar o mercado de TI no estado do Pará, a prevalência continua sendo masculina, isto pode ser observado pelas diferenças de contratações entre homens e mulheres no período de 2010 a 2019, onde o cargo em que houve mais contratações de mulheres no período foi o de digitador, cargo esse com menor exigência de qualificação técnica e, consequentemente, menor média salarial.

Diante do apresentado percebeu-se a predominancia do sexo masculino tanto nos cursos superiores quanto no mercado de TI do estado do Pará, sendo necessária a promoção de ações que incentivem a melhoria dos índices acerca da inserção das mulheres na área, tanto no ingresso em faculdades de tecnologia, como na permanência delas nos cursos e também na valorização da mão de obra feminina no mercado de trabalho. Em um contexto geral, é de suma importância o estabelecimento de políticas públicas que promovam a igualdade de condições e de salários entre os gêneros, como aumentar a oferta de creches e também a criação de leis que incentivem mulheres a estudar e a seguirem alguma profissão. Para estimular o ingresso de mulheres nas áreas de tecnologia, a adoção de algumas estratégias podem ser interessantes, como a criação de iniciativas que despertem o interesse das meninas, ainda na escola, para o estudo das disciplinas de exatas e uma melhor exposição nas escolas sobre as possibilidades de atuação das mulheres na área. Visando melhorar os índices de permanência das mulheres nos cursos de TI as próprias faculdades poderiam estabelecer algumas ações, como o fortalecimento de grupos que focassem na atuação de mulheres na área e a identificação de possíveis causas que desestimulam as meninas a finalizarem o curso, propondo soluções eficientes para esse contexto. Já no mercado de trabalho, o estabelecimento de campanhas que desmistifiquem a atuação de mulheres na área.

\section{REFERENCES}

[1] Instituto Nacional de Estudos e Pesquisas Educacionais. Censo da educação superior: Sinopse estatística, December 2019. URL https://www.gov.br/inep/pt-br/areas-de-atuacao/pesquisas- estatisticas-eindicadores/censo-da-educacao-superior/resultados.

[2] Juliana Schwartz. Mulheres na informática: quais foram as pioneiras? cadernos pagu, (27):255-278, 2006.

[3] Beatriz Leal Tamandaré, Flaviane Ribeiro Nascimento, Ivanildo Antônio dos Santos, and Letícia Martins Freitas Rocha. Discurso de masculinidade e feminilidade presentes no curso de engenharia civil do ifba-campus eunápolis. Revista PINDORAMA, 8(8):14-14, 2019.

[4] Softex. Estudo da softex mapeia a participação das mulheres no setor de ti, March 2020. URL https://softex.br/estudo-da-softex-mapeia-a-participacao-dasmulheres-no-setor-de-ti/.

[5] Julia Beckhusen. Occupations in information technology. US Department of Commerce, Economics and Statistics Administration, US ..., 2016.

[6] The Guardian. Why are there so few women in tech? the truth behind the google memo, August 2017. URL https://www.theguardian.com/lifeandstyle/2017/ aug/08/why-are-there-so-few-women-in-tech-the-truth-behind-the-googlememo.

[7] Unesco. Decifrar o código: educação de meninas e mulheres em ciências, tecnologia, engenharia e matemática (stem). Technical report, Organização das Nações Unidas para a Educação, a Ciência e a Cultura., 2018.

[8] Marcel Maggion MAIA. Limites de gênero e presença feminina nos cursos superiores brasileiros do campo da computação. cadernos pagu, (46):223-244, 2016.

[9] Adriano Teixeira and Camila Vieira Posser. Mulheres que aprendem informática: Um estudo de gênero na área de ti. In Anais do Workshop de Informática na Escola, 


\section{Computer on the Beach}

volume 22, page 707, 2016.

[10] Laura Ribeiro, Glívia Barbosa, Ismael Silva, Flávio Coutinho, and Natália Santos. Um panorama da atuação da mulher na computação. In Anais do XIII Women in Information Technology, pages 1-10. SBC, 2019.

[11] D Nunes. Educação superior em computação, estatısticas 2071. Sociedade Brasileira de Computaçao-SBC, 7, 2016.

[12] Instituto Nacional de Estudos e Pesquisas Educacionais. Censo da educação superior 2018: notas estatísticas, December 2019.

[13] Elsevier (Amsterdam). Gender in the Global Research Landscape: Analysis of Research Performance Through a Gender Lens Across 20 Years, 12 Geographies, and 27 Subject Ares. Elsevier, 2017.

[14] Josilene A Moreira, Ricardo M Silva, and Maria Eulina P Carvalho. Cenários prospectivos: Uma visão do futuro da presença feminina em cursos de ciência da computação de uma instituição de ensino superior. In Anais do XXVI Workshop sobre Educação em Computação. SBC, 2018.

[15] Jordão Horta Nunes. Gênero e raça no trabalho em tecnologia da informação (ti). Ciências Sociais Unisinos, 52(3):383-395, 2016.

[16] Amália Alexandre Uamusse, Eugenia Flora Rosa Cossa, and Tatiana Kouleshova A mulher em cursos de ciências, tecnologia, engenharia e matemática no ensino superior moçambicano. Revista Estudos Feministas, 28(1), 2020.

[17] Bianca Caetano da Silva Martins Franco, Aimar Martins Lopes, and Vivaldo José Breternitz. Gestão da tecnologia da informação: preconceitos de gênero prejudicam a carreira de mulheres que atuam na área? Revista Brasileira em Tecnologia da Informação, 1(1):22-34, 2010.

[18] Cnp: Estudo mostra que mulheres recebem $30 \%$ a menos que homens no mercado de trabalho formal, November 2017. URL https://www.gov.br/fazenda/ptbr/assuntos/noticias/2017/dezembro/cnp-estudo-mostra-que-mulheres- recebem-30-a-menos-que-homens-no-mercado-de-trabalho-formal.

[19] Associação Brasileira das Empresas de Tecnologia da Informação e Comunicação. Relatório setorial de tic 2018: Inteligência e informação, November 2018. URL https://brasscom.org.br/wp-content/uploads/2019/05/BRI2-2019-003aRelat\%C3\%B3rio-Setorial-Compacto-v13.pdf.

[20] N. U CEPAL. Panorama social da américa latina 2018. documento informativo, November 2018. URL https://www.cepal.org/pt-br/publicaciones/44412-panoramasocial-america-latina-2018-documento-informativo.

[21] Associação Brasileira de Estágios, December 2018. URL https://abres.org.br/ estatisticas/.

[22] Associação Profissional das Entidades Mantenedoras de Estabelecimentos de Ensino Superior no Estado de São Paulo. Mapa do ensino superior no brasil, December 2020. URL https://www.semesp.org.br/mapa-do-ensino-superior/ edicao-10/dados-estados-e-regioes/norte/.

[23] Josy Silva do NASCIMENTO. Análise da participação de mulheres nos cursos de tecnologia da informação (ti) na universidade federal rural da amazônia no campus capitão poço-pa, 2019 .

[24] Tatiele Pereira DE SOUZA. A desigualdade de gÊnero no campo da tecnologia da informaÇÃo, 2017.

[25] Classificação Brasileira de Ocupações. Mapa do ensino superior no brasil, December 2002. URL https://empregabrasil.mte.gov.br/76/cbo/.

[26] Kecia Ferreira, Glívia Barbosa, and Silvia Albuquerque. Uma iniciativa para apoiar e empoderar alunas de ensino técnico e de graduação em computação. In Anais do XIII Women in Information Technology, pages 104-108. SBC, 2019.

[27] SBC. Diretrizes para ensino de computação na educação básica. Technical report, Sociedade Brasileira de Computação, 2018.

[28] RS Silva. Base nacional comum curricular. MEC, 2018 